\title{
THE RELATION BETWEEN PRIMIPARA COPING PATTERN AND THEIR KNOWLEDGE DURING THE TWO \& FOUR WEEKS POSTNATAL
}

\author{
${ }^{1}$ NahedAbd El-magaid Ibrahim Abu El-eneen, ${ }^{2}$ Hanan El-Sayed
}

Mohammed El-Sayed, ${ }^{3}$ Reda Abd EL-Hady, ${ }^{4}$ KamiliaRagab Abo shabana.'

${ }^{1}$ B.S.C nursing, Faculty of Nursing, Mansoura University.

${ }^{2}$ Assist.Prof. of Woman's Health and Midwifery, Faculty of Nursing, Mansoura University

${ }^{3}$ Prof. of Obstetrics and Gynecology, Faculty of Medicine, Ma.nsoura University.

${ }^{4}$ Prof .of Maternal and Neonatal Health nursing, Faculty of Nursing, Ain-Shams University

Email: tiger.female84@yahoo.com

\begin{abstract}
Aim: The aim of the study was to evaluate the relation between primipara coping pattern and their knowledge during the two and four weeks postnatal. Methods: Study design: The descriptive study design was utilized in this study. Study setting: The study was conducted in Kafer-Elsheekh General Hospital at postnatal unit and at home during the period from January 2015 to June 2015. Subjects of the study: A convenient sampling of 120 primipara mothers. Tool:Two tools were used for data collection : A structured interview questionnaire to assess general characteristics of women, questions to assess the primipara knowledge about the postpartum, and coping scale to assess positive and negative coping at the two and four weeks postpartum. Results: The present study findings revealed that there was a significant difference between total scores of knowledge \&positive and negative coping at two weeks also there was a statistical significantly difference of knowledge and negative coping at four weeks postpartum. The total mean of positive coping during postpartum at fourth week is significantly higher than at the second week. There was a significant difference between mean scores of negative coping among different ages at two weeks also, there was highly statistically significant difference between mean score of negative coping by increasing the level of education and job in two weeks and four weeks. Conclusion: Overall the results of the present study highlighted that there was increasing of positive coping by good knowledge at two week but there was no change at fourth week. Recommendation: Activating programs for information, health education and communication to enhance women positive coping and raise knowledge of health provider and society about postpartum stressor and how to cope with it positively.
\end{abstract}

Keywords:Coping, Postpartum, Primipara

\section{Introduction:}

Postpartum is a period started directly after the placenta expulsion and extended to sixth or eight weeks in which the pelvic organs return to the non-pregnant state, uterine involution. There are many physiological and psychological changes during this period so it is vital for mother and newborn and need a special care from everyone around them (Pillitteri, 2014). Moreover postpartum period is the most ignored period so the first week of the postpartum losses acting about half of the total postpartum losses, and the common of these happen through the first 24 hours after delivery (WHO, 2015). The chief reason of mother deaths in Africa representing as 34 percent from all deaths was hemorrhage, the major cause occurs during the postpartum, infection and sepsis privilege and additional 10 percent of deaths, all of this mean that the most of 
deaths occur through postpartum(WHO, 2015).

Also postpartum period is a stressful time, particularly for the primipara mother. The greatest challengeable for her is the deficiency of knowledge about the caring for her baby and herself and the new role attainment. Numerous primipara mothers felling over whelming be the requirements of the baby and her requirements and her relation to others so primipara mothers need a social support and special care to pass this period safe(Mickinney,2017).

Furthermore postpartum period has a physical, emotional, and psychological impact on the life of the women, particularly primiparous women, and includes the attainment of a new role and care-taking responsibilities with which mothers should cope. Numerous factors affect both the managing of this new skill and the well-being of primipara mothers as, anxiety, prenatal stress, and symptoms of physical discomfort, feeling of parental inefficacy, social support, and maladaptive coping strategies (Baston\& Hall, 2017). Model of stress, appraisal, and coping is theorized as a three phases. Firstly model is the primary appraisal, which in this phase, the person selects whether a possibly stressful condition is indeed, reason for concern. Phase two of the theory includes secondary appraisal, in which the person further assesses the needs of the circumstances in terms of how stressful they are, and initiates to decide methods of coping. In phase three of the model the individual engages in coping with the circumstances (Seaward, 2017).

Also, coping is consuming conscious energy to resolve individual and social problems, and seeking to control, reduce or accept stress or struggle. Coping may be negative or positive depend on the strategy used to deal with stress and new role and its stresses. Two common strategies for coping are well-known: strategy of problem-solving is exerting effort to ease dramatic situations, while the other strategy is the emotion-focused coping strategy focus on controlling the feelings attributes of a traumatic situation and possibly dramatic happenings. The study shows that no one uses one type only, but mix the all types of strategies to control over the life dramatic situations (Razurel et al., 2013).

\section{Significance of the study}

. In 2015, there were an estimated 43,9 per 100,000 live births maternal mortality rate worldwide. Most of the deaths occurred in developing countries. (World Health Organization 2016), 6-17\% are depressed and $28 \%$ among primipara mothers are suspected to need psychological help during the postnatal period, the strongest predictor of puerperal depression, followed by the lack of social support, distress, and a depression- related coping style.

It is important to investigate coping strategies of primipara mothers during the late postpartum period and knowledge of women about this period to instruct her and enhance her positive coping and minimize her negative coping

\section{Aim of the study:}

The aim of the present study was to evaluate the relation between primipara coping pattern and their knowledge during the two \& four week postnatal.

\section{Research question:}

Is there a relation between primipara coping pattern and their knowledge during the two \& four week postnatal week postnatal?

\section{Subjects and Method:}

Study design: Followed up descriptive study design.

Study setting: The present study was conducted at the postnatal unite of KaferElsheekh General Hospital and at home during six months from January 2015 to June 2015 
THE RELATION BETWEEN PRIMIPARA COPING PATTERN AND etc...

Sample: A convenient sampling was used for one hundred and twenty primipara mothers in the postnatal ward of KaferElsheekh General Hospital.

\section{Tools of Data Collection}

To achieve the aim of the study, two tools were used for data collection:

First tool: A structured interview schedule. It included two parts:

First part: Was designed to collect data about general characteristics of mothers as: age, level of education, occupation and residence.

Second part: Was designed to assess the mother knowledge about postnatal period, it was consisted of four questions as a meaning of postpartum, postpartum changes, postpartum complications and self-care measures to relief complains.

Scoring system: For knowledge was one for the incorrect answer, and two for the correct answer.

Second tool: Coping scale for postpartum mothers. It consists of two parts.

Part one: A positive coping skills. It was consisted of 24 positive coping skills to assess positive coping skills during the late postnatal period (after two and four weeks post-delivery).

Part two: A negative coping skills. It was consisted of 27 negative coping skills to assess negative coping skills during the late postnatal period (after two and four weeks post-delivery).

\section{The Pilot study}

The pilot study was performed before starting the collection of data for 12 primipara mother. This was done in order to assess the clarity \& applicability of the tools of data collection and the time needed for completion

\section{Ethical considerations}

- The researcher obtained the ethical approval from the research ethics committee of the faculty of nursing, Mansoura University.

- The researcher was clarifying the aim of the study to each mother included in the study and assuring the confidentiality and privacy of data collected.

- Oral consent is obtained from each mother to participate in the study. Mothers were informed that they are allowed to choose to take themself out from the study when they want. The study maneuvers couldn't entail any harm to participant, and tools of data collection did not touch the mother's dignity, cultural or religious aspects.

\section{Statistical Analysis.}

Data were collected, computed and statistically analyzed using SPSS soft war program version 16 (Statistical Package of Social Sciences). The qualitative variables were presented in tables as frequencies and percentages while continuous quantitative variables were presented as mean $\pm S \mathrm{D}$. A comparison was done using Chi square $\left(\mathrm{X}^{2}\right.$ ) for qualitative variables with using fisher exact test where expected cell less was than 5. Studded t test was used for continuous quantitative variables in two groups and (one way Anova) for comparison of more than 2 groups (F test). The difference is considered significant at $\mathrm{P} \leq 0.05$. 
NahedAbd El-magaid Ibrahim Abu El-eneen et., al.

Results

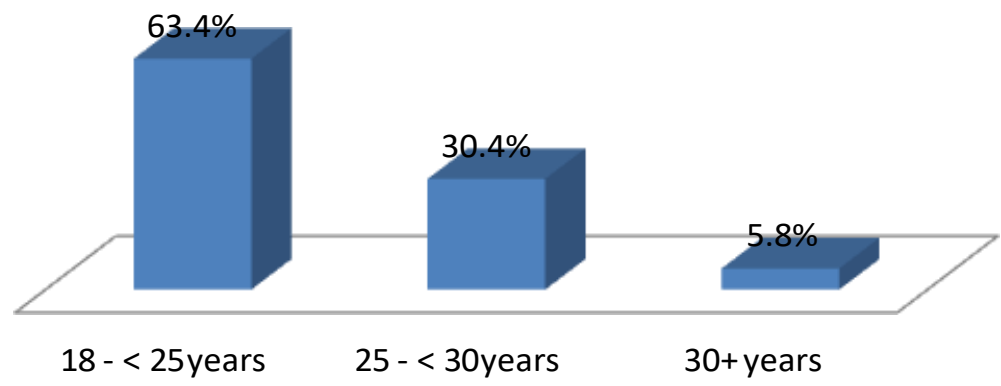

Figure (1) Age of the studied group.

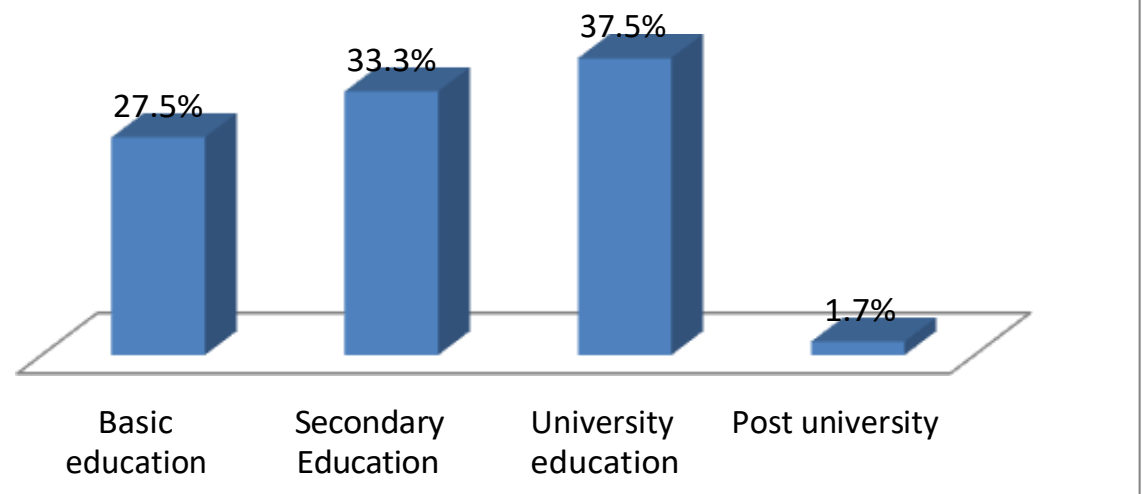

Figure (2): Education of the studied group.

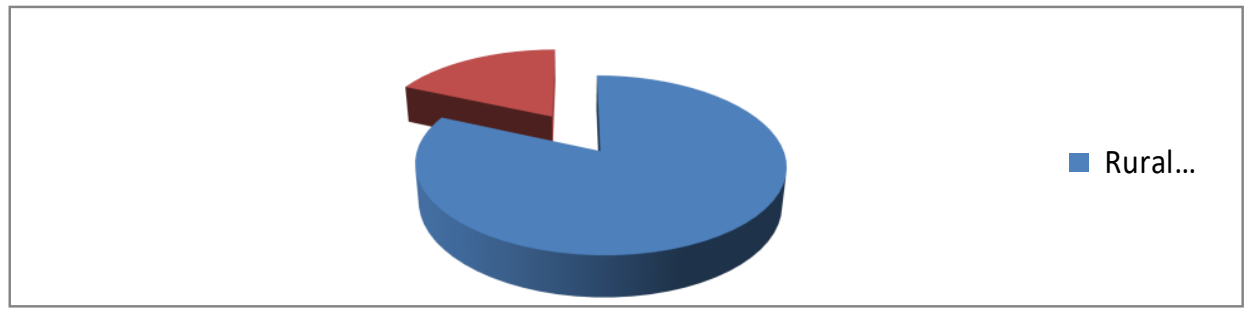

Figure (3): Residence of the studied group. 


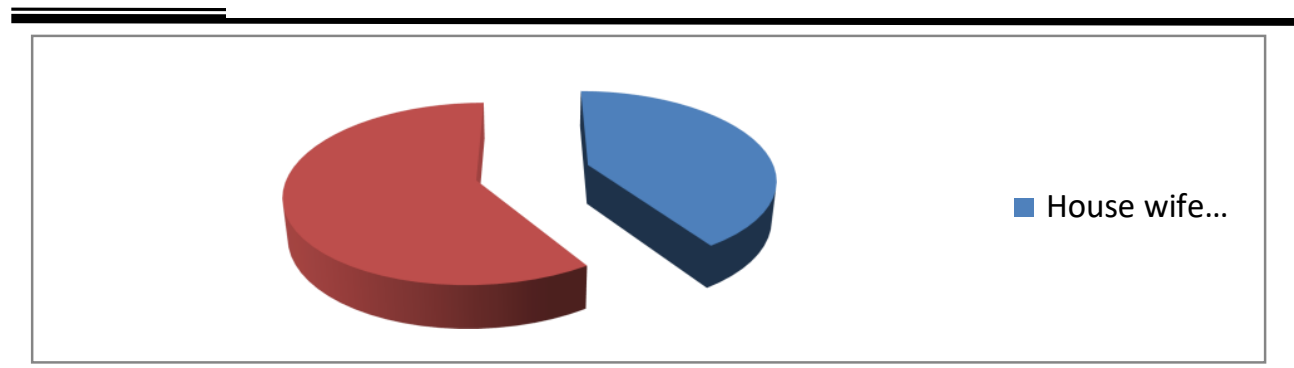

Figure (4): Job of the studied group.

Figure 1, 2, 3 and 4: Shows the general characteristics of the studied group. Most of the mothers were aged less than 30 years $(94 \%)$. (70.8\%) were secondary and university education. About $60 \%$ were working and most of them $(81.7 \%)$ were from rural area.

Table (1) Frequency distribution among the studied group according to knowledge related to the postnatal period.

\begin{tabular}{|l|l|l|l|l|}
\hline \multirow{2}{*}{ Items } & Incorrect & Correct \\
\cline { 2 - 5 } & No & $\%$ & No & $\%$ \\
\hline Meaning of postpartum & 35 & 29.2 & $\mathbf{8 5}$ & $\mathbf{7 0 . 8}$ \\
\hline Postpartum changes & 108 & $\mathbf{9 0 . 0}$ & 12 & $\mathbf{1 0 . 0}$ \\
\hline Postpartum problems & 119 & $\mathbf{9 9 . 2}$ & 1 & $\mathbf{0 . 8}$ \\
\hline Newborn / Mother care & $\mathbf{1 0 7}$ & $\mathbf{8 9 . 1}$ & $\mathbf{1 3}$ & $\mathbf{1 0 . 8}$ \\
\hline
\end{tabular}

Table (1) shows the knowledge of mothers about postnatal period. It revealed that about three quarters $(70.8 \%)$ of the mother had the correct meaning of the postnatal period. About $(90.0 \%, 99.2 \%, 89.1 \%$ respectably) of mothers had incorrect knowledge about postpartum changes, postpartum problems and newborn \& mother care.

Table (2) Comparison between mothers total positive coping score at two weeks and four weeks postpartum.

\begin{tabular}{|l|l|l|}
\hline Total score & At two weeks & At four weeks \\
\hline Mean \pm S D & $16.875 \pm 2.955$ & $19.383 \pm 2.686$ \\
\hline Paired t test $=9.224$, P0.000 & \\
\hline
\end{tabular}

Table (2) shows the mean score of total positive coping at two and four weeks. There was a significant increase in the total score after four weeks compared to its level in two weeks $(\mathrm{P}=0.000)$.

Table (3) Comparison between mother total negative coping score at two weeks and four weeks postpartum

\begin{tabular}{|l|l|l|}
\hline Total score & At two weeks & At four weeks \\
\hline Mean \pm S D & $9.858 \pm 4.911$ & $6.483 \pm 4.535$ \\
\hline Paired t test $=9.433$, P0.000 & \\
\hline
\end{tabular}

Table (3) shows the mean score of total negative coping at two and four weeks. There was a significant difference in the total score after four weeks compared to its level in two weeks $(\mathrm{P}=0.000)$. 
NahedAbd El-magaid Ibrahim Abu El-eneen et., al.

Table (4): Relationship between studied group knowledge level and the average score of
coping
\begin{tabular}{|l|l|l|c|}
\hline Type of coping & $\begin{array}{l}\text { Fair } \\
\text { Knowledge } \\
(\mathbf{1 0 1})\end{array}$ & $\begin{array}{l}\text { Good } \\
\text { knowledge } \\
(\mathbf{1 9 )}\end{array}$ & Significant test \\
\hline $\begin{array}{l}\text { Positive coping at } \mathbf{2} \\
\text { weeks }\end{array}$ & $16.64 \pm 2.89$ & $18.11 \pm 3.03$ & $\mathrm{t}=2.003, \mathrm{P} 0.047$ \\
\hline $\begin{array}{l}\text { Negative coping at } \mathbf{2} \\
\text { weeks }\end{array}$ & $10.40 \pm 4.83$ & $7.00 \pm 4.43$ & $\mathrm{t}=2.846, \mathrm{P} 0.005$ \\
\hline $\begin{array}{l}\text { Positive coping at } \mathbf{4} \\
\text { weeks }\end{array}$ & $19.33 \pm 2.73$ & $19.68 \pm 2.45$ & $\mathrm{t}=0.531, \mathrm{P} 0.597$ \\
\hline $\begin{array}{l}\text { Negative coping at } \mathbf{4} \\
\text { weeks }\end{array}$ & $6.90 \pm 4.64$ & $4.26 \pm 3.17$ & $\mathrm{t}=2.370, \mathrm{P} 0.019$ \\
\hline
\end{tabular}

Table (4) shows the relationship between studied group knowledge level and the average score of coping. It is revealed significant difference between total scores of knowledge \&positive and negative coping at two weeks $(\mathrm{P}=0.047, \mathrm{P}=0.005)$ (respectively), also there was a statistical significantly difference of knowledge and negative coping at four weeks postpartum $(\mathrm{p}=0.019)$.

Table (5) Relationship between the general characteristics of the studied group and their positive coping score.

\begin{tabular}{|l|l|l|l|}
\hline \multicolumn{1}{|c|}{ Items } & No & \multicolumn{1}{|c|}{$\begin{array}{c}\text { Positive coping score } \\
\text { (2weeks) }\end{array}$} & $\begin{array}{c}\text { Positive coping score } \\
\text { (4weeks) }\end{array}$ \\
\hline Age & $\mathbf{7 6}$ & $16.79 \pm 3.31$ & $18.73 \pm 2.84$ \\
$18-<25 y$ & $\mathbf{7 3}$ & $17.00 \pm 2.32$ & $20.50 \pm 2.01$ \\
$25-<30 \mathrm{y}$ & $\mathbf{7}$ & $17.14 \pm 1.95$ & $20.71 \pm 1.80$ \\
$30+$ & & $\mathrm{F}=0.092, \mathrm{P} 0.912$ & $\mathrm{~F}=6.599, \mathrm{P} 0.002$ \\
\hline Significance test & & $15.84 \pm 2.67$ & $18.88 \pm 2.66$ \\
\hline Education. & $\mathbf{3 3}$ & $16.83 \pm 2.17$ & $19.25 \pm 3.15$ \\
Basic education & $\mathbf{4 0}$ & $17.64 \pm 3.56$ & $19.87 \pm 2.23$ \\
Secondary & $\mathbf{4 5}$ & $17.50 \pm 3.53$ & $19.38 \pm 2.12$ \\
University & $\mathbf{2}$ & $\mathrm{F}=2.466, \mathrm{P} 0.066$ & $\mathrm{~F}=0.983, \mathrm{P} 0.441$ \\
Post university & & & $19.19 \pm 2.56$ \\
\hline Significance test & & $16.60 \pm 2.91$ & $20.23 \pm 3.12$ \\
\hline Residence & $\mathbf{9 8}$ & $18.09 \pm 2.8$ & $\mathrm{t}=1.643, \mathrm{P} 0.103$ \\
Rural & $\mathbf{2 2}$ & $\mathrm{t}=2.169, \mathrm{P} 0.032$ & $19.42 \pm 2.65$ \\
Urban & & $16.18 \pm 2.93$ & $19.35 \pm 2.73$ \\
\hline Significance test & $\mathbf{4 9}$ & $17.35 \pm 2.90$ & $\mathrm{t}=0.153, \mathrm{P} 0.879$ \\
\hline Occupation & $\mathbf{7 1}$ & $\mathrm{t}=2.162, \mathrm{P} 0.033$ & \\
Housewife & &
\end{tabular}

Table (5) shows the relationship between the general characteristics of the studied group and positive coping score. It is revealed significant rising of the score with increasing age at four weeks $(\mathrm{P}=0.002)$. While there was statistically significant difference between rural 
THE RELATION BETWEEN PRIMIPARA COPING PATTERN AND etc...

\&urban mothers at two weeks postpartum $(\mathrm{P}=0.032)$. Also, there was a statistical difference between the house wife \& working mothers at two weeks $(\mathrm{P}=0.033)$.

Table (6) Relationship between the general characteristics of the studied group and their negative coping score.

\begin{tabular}{|l|l|l|l|}
\hline \multicolumn{1}{|c|}{ Items } & No & \multicolumn{1}{|c|}{$\begin{array}{c}\text { Negative coping } \\
\text { score(2weeks) }\end{array}$} & \multicolumn{1}{c|}{$\begin{array}{c}\text { Negative coping } \\
\text { score(4weeks) }\end{array}$} \\
\hline Age & & & \\
$18-<25$ & $\mathbf{7 6}$ & $9.00 \pm 4.99$ & $6.21 \pm 4.96$ \\
$25-<30$ & $\mathbf{3 7}$ & $11.19 \pm 4.39$ & $6.76 \pm 3.81$ \\
$30+$ & $\mathbf{7}$ & $12.14 \pm 4.91$ & $8.00 \pm 3.00$ \\
\hline Significance test & $\mathrm{F}=3.409, \mathrm{P} 0.036$ & $\mathrm{~F}=0.592, \mathrm{P} 0.555$ \\
\hline Education & & & \\
Preparatory & $\mathbf{3 3}$ & $11.94 \pm 4.76$ & $9.16 \pm 5.11$ \\
Secondary & $\mathbf{4 0}$ & $10.03 \pm 4.84$ & $6.70 \pm 4.12$ \\
University & $\mathbf{4 5}$ & $8.31 \pm 4.66$ & $4.46 \pm 3.38$ \\
Post university & $\mathbf{2}$ & $7.00 \pm 1.41$ & $3.50 \pm 2.12$ \\
\hline Significance test & & $\mathrm{F}=3.983, \mathrm{P} 0.010$ & $\mathrm{~F}=8.417, \mathrm{P} 0.000$ \\
\hline Residence & & & $6.47 \pm 4.58$ \\
Rural & $\mathbf{9 8}$ & $9.76 \pm 4.76$ & $6.54 \pm 4.40$ \\
\hline Urban & $\mathbf{2 2}$ & $10.27 \pm 5.61$ & $\mathrm{t}=0.071, \mathrm{P} 0.944$ \\
\hline Significance test & $\mathrm{t}=0.436, \mathrm{P} 0.633$ & $8.08 \pm 4.99$ \\
\hline Occupation & & & $5.38 \pm 3.85$ \\
\hline House wife & $\mathbf{4 9}$ & $11.67 \pm 4.82$ & $\mathrm{t}=3.341, \mathrm{P} 0.001$ \\
\hline Working & $\mathbf{7 1}$ & $8.611 \pm 4.59$ & $\mathrm{t}=3.521, \mathrm{P} 0.001$ \\
\hline Significance test &
\end{tabular}

Table (6) shows the relationship between the general characteristics of the studied group and their negative coping score. It is revealed difference between mean scores of negative coping among different ages at two weeks $(\mathrm{P}=0.036)$. Also, there was highly statistically significant difference between mean scores of negative coping by increasing the level of education and occupation at two weeks and four weeks else, $(\mathrm{P}=0.000)$

\section{. Discussion}

The aim of the present study was to evaluate the relation between the primipara coping pattern and their knowledge during the two and the four weeks postpartum. The present study results revealed that there was a significant difference between total scores of knowledge \&positive and negative coping at two weeks also there was a statistical significant difference of knowledge and negative coping at four weeks postpartum, so the present study results answer the research question is there a relation between primipara coping patterns and their knowledge during the two \& four week postnatal?
The present study results were supported by Liu et al. (2012)who study effects of maternal confidence and competence on maternal parenting stress in newborn care in Taiwan and found that primipara mothers were stressed with newborn care and had difficult to adapt to maternal role firstly and decrease this stress and cope positively with increasing their baby age. While the present study results were in disagree with Digregorio (2013) who studied stress appraisal, coping response, and acculturation level as predictors of postpartum depression symptoms in women of Mexican origin which found that nearly to half cannot cope positively or decrease negative 
coping and can not to adapt to the new role.

The present study results showed that, all study group listening to Qur'an to get rid of stress because they can't pray in the same the present study findings were supported by Jaisy(2010) who assess the level of stress and coping strategies among primi postnatal mother with selected hospital at Managalore and found that all of them prying to get rid their stress. The present study sample and Jaisy study group all of them resorting to Allah everybody according to their religious to help them and pass their stress in a positive way.

The present study results showed that two third of the study sample talk about their physical and psychological fatigue to become comfortable and feel good. The present study results were in agreement with Jaisy (2010) who reported that about more than one third of her study group coped well by expressing their feelings to others. Moreover, reported that about one quarter among the study group resorted to reading books in generally to decrease their stress while the present study revealed that three quarters of the study group reading about postpartum and how to care of her baby.

Concerning, care of the mother, the current study finding showed that near to one quarter of mother reported that they have no time to care for her and there was a significant difference in this at four weak because the resulting decreased to one eighth at the four weeks and that's because they used their time well and coped well.These results were supported by Piontkowski (2011) who study first baby, first year: gratitude and emotional approach coping as predictors of adjustments and life satisfaction during the transition to motherhood in the United States and reported that one eighth felling globally distressed and overwhelming.
As regards total positive score. The present study results revealed that there was a significance difference in total positive coping score after four weeks compared to its level after two weeks. The present study results were in agreement with Weiss et al. (2009) and study adaptation, postpartum concerns and learning need in the first two weeks after caesarean birth in the United States who reported that there was a moderate level of adaptation over all emotional, social, physical and functional adaptation.

The current study findings revealed that more than half of the participants at two weeks postpartum were reading about postpartum and how baby care and this percentage increased to three quarters at four weeks without significance difference. These results were supported by Kuo et al. (2009) who study the effects of internet education program on newborn care In Taiwan and found that the participants who reading about postpartum and baby care more knowledgeable and had confidant about baby care coping well and increasing her confidence and facilitate her caring with her newborn and facilitate her adaptation to maternal role.

The present study results revealed that more than half of the participants go to the close friend to talk about their problems as a kind positive coping to talk about their stressor. The current study results were similar to Osman et al. (2014) who study intervention to reduce postpartum stress in first time mothers and reported that more than half of them watching a film about post-partum stressor and how dealing with, and more than one third of them go to hotline call to reduce stress and found both of them had a significant reduce of stress. The agreement of results may due to talking about postpartum stressors or watching a film about the problem and how to deal with it reduce the stress. 
THE RELATION BETWEEN PRIMIPARA COPING PATTERN AND etc...

The present study revealed that there was a significance difference increase in total positive coping at four weeks compared with its level at two weeks. The current study findings were in the same line with Ahan et al (2007) who study predictors of women's postpartum health status in the first 3 months after child birth and found sense of mastery and controlling overall the situation leading to adaptation to the parenthood and positive coping which producing good maternal health outcome. The agreement of results may be due to just the mother achieve success in new role skills give her sense of mastery over her stressor and enhance using of positive coping.

In addition the present study revealed that there was significant difference in practice of breastfeeding as a positive coping which reach to almost all of participants practice well at the fourth week, on the other hand the study revealed that there was significant difference in practice breastfeeding and fear of falling the baby decreasing negative coping to reach almost all of them become practice breastfeeding well. The present study results were in contrast with Girish \&Gandhimathi (2015) who study primipara mother's knowledge, attitude and practice of breastfeeding and founded less than one tenth of the participant having a good practice breastfeeding, more than half of them have average practice breast feeding and one third of them having poor practice breast feeding. The contrast of results may be due to the difference of thinking between countries, Egyptian women loved to breastfeed and trying for success in it.

The present study results revealed that positive coping, enhanced by experience with trial and error, so there was a significant difference in positive coping at the four week compared with its level in the two weeks and like this the negative coping which decreased in the four week rather than the two week that because the mother had adapted to the new role and had more competence to face their challenges with newborn and postpartum stressor.The current study findings were in the same line with Kuo et al (2012)who studies, parenting confidence and needs for parents of newborn in Taiwan, which found that the postnatal period is a time for learning how to care with their baby and feeling of fulfillment with parenthood increase their confidence and adaptation and enhance positive coping. The agreement may be due to the gretest way to learn is the error and trial

The present study results were in agreement with Hung (2007) who study the psychological consequences for primipara and multipara in Taiwan reported that there were a high percentage of all group study supported from relative, family and friends and this agreement with studies result may be due to they are primi and this the first time to be a mother or dealing with the postpartum stressors. As regards to body images the current study, findings showed that a small percentage of the study sample had worried about body image. While the present study results were contrasted with Hung (2007) who founded high percentage of his study group had worried about personal appearance and felt negative about their postpartum bodies. This contrast between the studies result may be due to the Egyptian concept that is normal to have overweight through pregnancy and during the breastfeeding period.

Regarding to negative coping the current study, findings was revealed that there were significant differences in the total score of negative coping after four weeks compared to its level in two weeks. The present study results in the same line with Shorey et al. (2014) who study perceptions of primiparas in a postnatal 
psych education program in Singapore and found that most of participant experienced negative emotions and felt overwhelmed with the challenges of postnatal period and then move to be confident and better both physically and emotionally to cope with the challenges in the postnatal period. This agreement of the studies result may be due to everybody can learn by trial and error and every day passes in the postpartum period move to better physically and all of this leads to decreasing negative coping.

In relation to mother knowledge and negative coping, the present study results revealed that there was a significance difference in the relation between correct and incorrect answers of mother's knowledge and negative coping related newborn and mother care. The present study results were supported by Weiss et al.(2009) who reported that half of participants had correct answers and response related to newborn care but found three items had lowest correct answers and response which found approximately one quarter of them had a correct answers about maternal appropriate food and fluid, only one tenth of them had a knowledge about the amount of milk consuming per day and lastly one third of them had knowledge about maternal temperature that need a call to provider.

\section{Conclusion}

Based on the findings of the study, the following can be concluded that, overall findings, there was a significant increase in total positive coping score after four weeks postpartum compared to its level in two weeks. As regards to the relation between positive coping and knowledge of mothers, there was increasing of positive coping by good knowledge at two weeks but there was no change at four week.
Recommendations

In the light of the study findings, the

following are recommended

1. Provide health education to women during postnatal care about the baby and mother care and postpartum stressor and how cope positively to overcome this period safely mental and physical.

2. Continuous training program for midwife, nurse about postpartum changes and stressors and how women can cope positively and increase communication skills of midwifery.

3. Using antenatal visits to increase pregnant women awareness and knowledge about baby care and how to deal with him and women changes with providing handout and guideline about mother and baby care during postnatal.

\section{References}

1. Ahan S, \& Youngblut JAM (2007): Predictors of women's postpartum health status in the first 3 months after child birth, Asian nursing research; 1(2) :136-146.

2. Baston H, \& Hall J (2017): Midwifery essential postnatal: Emotional wellbeing following birth. Second ed, Elsevier, China, PP122144.

3. Digregorio R. M., (2013): Stress appraisal, coping response, and acculturation level as predictors of postpartum depression symptoms in women of Mexican origin, ETD collection for university of Texas, Elaps. AAI 3594333. https://digitalcommon.utep.edu/disserta tions/AAI3594333.

4. Epel, E. S., \& Lithgow, G. J. (2014): Stress biology and aging mechanisms: Toward understanding the deep connection between adaptation to stress and longevity. Biological 
THE RELATION BETWEEN PRIMIPARA COPING PATTERN AND etc...

Sciences and Medical Sciences Journal, 69(S1), S10-6.

5. Folkman $S$ (2013): Stress, appraisal and coping. In: Gellman M.D., Turner J.R. (eds) Encyclopedia of behavioral medicine. Springer, New York, https://doi.org/10.1007/978-1-44191005-9, access Aprile, 2014.

6. Girish \&Gandhimathi (2015): Primipara mother's knowledge, attitude and practice of breastfeeding, http://medical.cloudjournals.com/index.php/IJANSP/article /view/Med-222,acces May,2016.

7. Hung, (2007): The psychological consequences for primipara and multi .Kaohsiung J Med ; 23:352-60.

8. Jaisy T. (2010): A study to assess the level of stress and coping strategies among primi postnatal mothers with a view to develop self-model in selected hospital at Mangalore,thesis in university of health science Bangalore Karantaka.

9. Kuo CP., Chung HL., Lee SH., \&Lao WC.(2012): Parenting confidence and needs for parents of newborn in Taiwan, Iranian journal of pediatrics; 22 (2) P177-184.

10. Kuo SC, Chen YS, Kuan- Lin KC,\& Lee TY (2009: Study the effects of internet education program on newborn care In Taiwan. Journal clinical nursing; 18(11): 1592-1601.

11. Liu C., Chen Y, Yeh Y. \& Hsieh Y. (2012): Effects of maternal confidence and competence on maternal parenting stress in new born care in Taiwan, JAN informing practice and policy, word wide through and scholarship; 68(4) : 908-918.

12. Mickinney ES, Jamis S, Murray S., \&Nelson K. (2017): Maternal- child nursing: Maternal nursing care, postpartum adaptation. $5^{\text {th }}$ ed, Elsevier,Canada,PP395-424.
13. Osman H., Saliba S, Chaaya M, \&Naasan G (2014): Intervention to reduce postpartum stress in first time mother: A randomized control, BMC women's health; 68(74) P 14- 25.

14. Pillitteri A(2014): Study guided to accompany maternal and child health nursing: Care of child bearing and childbearing family. $7^{\text {th }} \mathrm{ed}$, Lippincott Williams \& Wilkins Ca, Philadelphia, PP $423-426$

15. Piontkowski S (2011): First baby, first year: gratitude and emotional approach coping as predictors of adjustments and life satisfaction during the transition to motherhood, United States, University of Maryland, College Park, ProQuest Publishing, 1495732.

16. Razurel C, Kaiser B, Sellenet C, \&Epiney M (2013): Relation between perceived stress, social support, and coping strategies and maternal wellbeing: A review of the literature. Women Health 53:74-99.

17.Seaward BL(2017): Managing stress, principles and strategies for health and wellbeing: The nature of stress. $9^{\text {th }} \mathrm{ed}$, Jones\& Bartlet Learning, USA,PP $62-$ 82.

18. Shorey S, HE Hong- Gu, Chong Yap Seng, \&Wai-chi S, (2014): Perception of primipara on a postnatal psychoeducation program: the process evaluation, Singapoure. Journal of midwifery \& women's health 71(6):1260-1273.

19. Weiss M, Fawcett J, \& Cynthaaber (2009): Adaptation, postpartum concerns and learning needs in first two weeks after cesarean birth, Journal of clinical nursing ; 18 (21):2938-2948.

20.WHO (2016): The lancet, science direct;387 (10017):462-474. https://doi.org/10.1016/S01406736(15)00838-7 access, Augst, 2017 